\title{
Human Papilloma Virus Infection and Anal Squamous Intraepithelial Lesions
}

\author{
Laura Svidler López, MD ${ }^{1}$ Luciana La Rosa, MD²,3 \\ ${ }^{1}$ Department of Surgery, Hospital General de Agudos Juan A. \\ Fernández, Buenos Aires, Argentina \\ 2 Department of Surgery, Centro de Educación Médica e \\ Investigaciones clínicas, Buenos Aires, Argentina \\ ${ }^{3}$ Centro Privado de Cirugía y Coloproctología, Buenos Aires, \\ Argentina
}

\begin{abstract}
Address for correspondence Laura Svidler López, MD, Department of Surgery, Hospital General de Agudos Juan A. Fernández, Cerviño 3356, C1425AGP CABA, Argentina

(e-mail: lausvidlerlopez@gmail.com; lucianalarosa@gmail.com).
\end{abstract}

Clin Colon Rectal Surg 2019;32:347-357.
Abstract
Keywords
- HPV
- ASIL
- HIV
- PAIN
- AIN
- Bowen's disease
- Bowenoid papulosis
- squamous cell carcinoma

This article addresses the natural history of the human papilloma virus (HPV) infection to anal squamous intraepithelial lesions, and onto squamous cell carcinoma of the anus. This article provides overviews of the virology, pathophysiology, nomenclature, classification, historical terms, risk factors, clinical evaluation, differential diagnosis, and treatment of HPV infection and its sequelae.
Human papilloma virus (HPV) is the most common sexually transmitted disease (STD) throughout the world. ${ }^{1}$ The vast majority of sexually active adults are affected at some point in their lives. Most will have no symptoms or self-limited anogenital lesions. There are 150 genotypes. Forty can infect the anogenital organs. ${ }^{2}$ HPV subtypes are categorized as low or high risk according to their propensity to progress to squamous intraepithelial lesions (SIL). SIL are also stratified into low- or high-grade SIL (LG-SIL and HG-SIL) based on their oncogenic potential of progressing to anal squamous cell carcinoma (SCC). LG-SIL is relatively innocuous. HG-SIL can progress to anal SCC in a minority of cases. However, 90\% of anal SCC are attributable to HPV infections $^{3}$ (-Fig. 1).

HPV infection predominantly affects the anogenital regions but rare naso- and oropharyngeal infections do occur. Progression to intraepithelial neoplasia (-IN) can involve the cervix (CIN), vagina (VaIN), vulva (VIN), penis (PeIN), anus (AIN), and perianal (PAIN) regions. ${ }^{4}$ Anal squamous intraepithelial lesions (ASIL) include two anatomic groups of pathologies-PAIN and AIN. The former involves keratinized integumentary tissue outside the anus, while the latter refers to nonkeratinized epithelium within the anal canal extending $8 \mathrm{~cm}$ into the rectum. - Table 1 summarizes the relevant pathologic terms, their abbreviations, anatomic locations, and their clinical relevance.

\section{Virology}

Forty subtypes of HPV known to infect human anogenital regions are stratified according to their oncogenic propensity (-Table 2). HPV genotypes 6 and 11 are of low risk. They produce the majority of LG-SIL. ${ }^{5}$ Persistent high-risk HPV infection is associated with HG-SIL. ${ }^{6}$ Genotypes 16 and 18 are among the most common precursors of SCC. In one series, genotype 16 was found in $81 \%$ of SCC. Genotype 18 was found in $4 \%{ }^{7}$

\section{Pathophysiology}

HPV is transmitted through direct contact with infected mucosa or skin. It invades the cells of the basal layer of the
Issue Theme Perianal Dermatology; Guest Editors: Adrián E. Ortega, MD, FASCRS, and Xavier Delgadillo, MD, EBSQ-C
Copyright (c) 2019 by Thieme Medical Publishers, Inc., 333 Seventh Avenue, New York, NY 10001, USA. Tel: +1(212) 584-4662.
DOI https://doi.org/ 10.1055/s-0039-1687830. ISSN 1531-0043. 


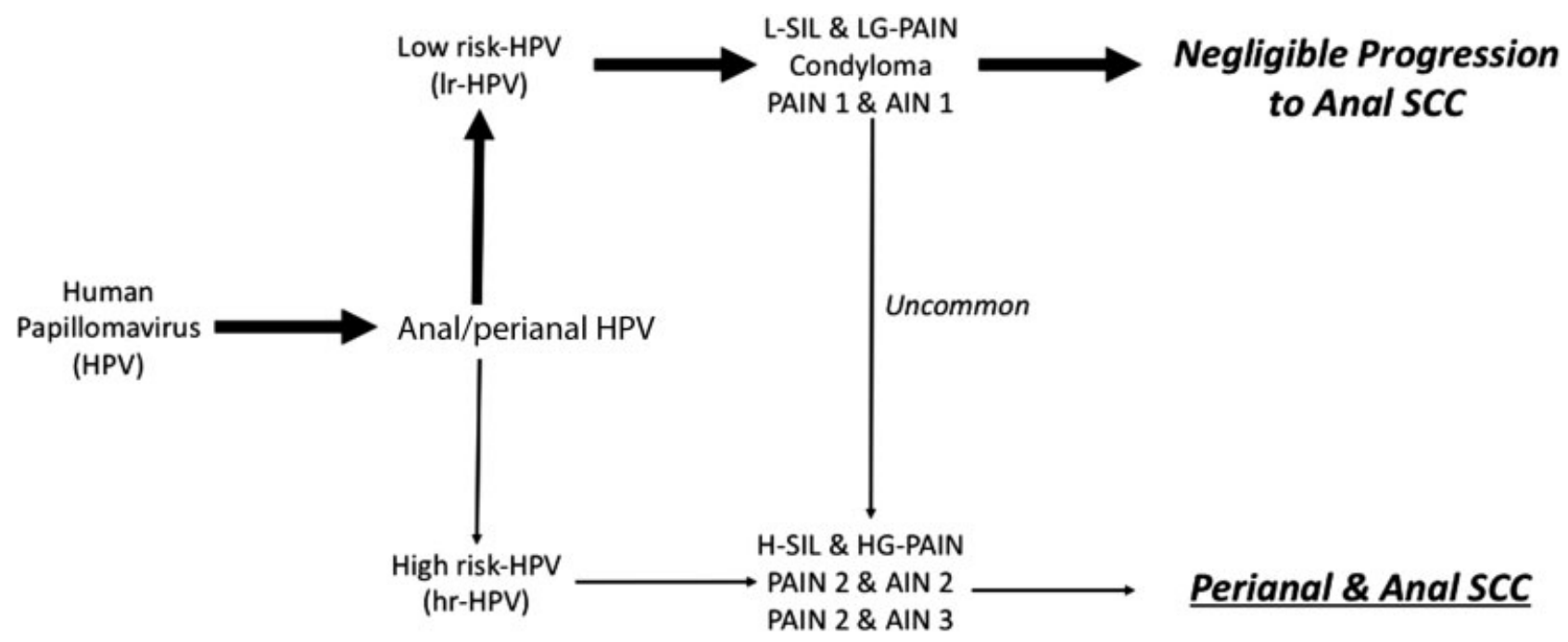

Fig. 1 An overview of the natural history of human papilloma virus (HPV) infection. Note that condyloma and intraepithelial neoplasia 1 (perianal intraepithelial neoplasia [PAIN1] and anus intraepithelial neoplasia [AIN 1]) are considered low oncogenic risk (low-grade squamous intraepithelial lesion [LG-SIL]) and are the more common outcome (thick arrows). Abbreviation: SCC, squamous cell carcinoma.

Table 1 LG-SIL are the more common outcome (thick arrows)

\begin{tabular}{|c|c|c|c|c|}
\hline Abbreviation & \multicolumn{2}{|l|}{ Pathology } & $\begin{array}{l}\text { Anatomic } \\
\text { location }\end{array}$ & ASIL relevance/equivalence \\
\hline ASIL & \multicolumn{2}{|c|}{ Anal squamous intraepithelial lesion } & $\begin{array}{l}\text { Anal canal and } \\
\text { perianal }\end{array}$ & \\
\hline SIL & \multicolumn{2}{|l|}{ Squamous intraepithelial lesion } & Ubiquitous & \\
\hline LG-SIL & \multicolumn{2}{|c|}{ Low-grade squamous intraepithelial lesion } & Ubiquitous & Not precancerous \\
\hline HG-SIL & \multicolumn{2}{|c|}{ High-grade squamous intraepithelial lesion } & Ubiquitous & Pre-cancerous \\
\hline$-\mathrm{IN}$ & \multicolumn{2}{|l|}{ Intraepithelial neoplasia } & Ubiquitous & \\
\hline PAIN & \multicolumn{2}{|l|}{ Perianal intraepithelial neoplasia } & Perianal & \\
\hline LG-PAIN & \multicolumn{2}{|c|}{ Low-grade perianal intraepithelial neoplasia } & Perianal & Perianal LG-SIL \\
\hline HG-PAIN & \multicolumn{2}{|c|}{ High-grade perianal intraepithelial neoplasia } & Perianal & Perianal HG-SIL \\
\hline AIN 1 & Anal intraepithelial neoplasia 1 & \multirow{3}{*}{$\begin{array}{l}\text { Reflects } \\
\text { Intradermal Depth: } \\
3>2>1\end{array}$} & Anal Canal & Anal canal LG-SIL \\
\hline AIN 2 & Anal intraepithelial neoplasia 2 & & Anal Canal & Anal canal LG-SIL versus HG-SIL ${ }^{\mathrm{C}}$ \\
\hline AIN 3 & Anal intraepithelial neoplasia 3 & & Anal Canal & Anal canal HG-SIL \\
\hline HPV & \multicolumn{2}{|l|}{ Human papilloma virus } & Ubiquitous $^{\mathrm{a}}$ & \\
\hline Ir-HPV & \multicolumn{2}{|l|}{ Low-risk human papilloma virus } & Ubiquitous & Progresses to LG-SIL \\
\hline Hr-HPV & \multicolumn{2}{|l|}{ High-risk human papilloma virus } & Ubiquitous & Progresses to HG-SIL \\
\hline LGT -IN & \multicolumn{2}{|c|}{ Lower genital tract intraepithelial neoplasia } & $\begin{array}{l}\text { Cervix, vagina, } \\
\text { vulva }\end{array}$ & Increases risk for AIN in females \\
\hline SCC & \multicolumn{2}{|l|}{ Squamous cell carcinoma } & Ubiquitous $^{\mathrm{b}}$ & \\
\hline HGD & \multicolumn{2}{|l|}{ High-grade dysplasia $^{d}$} & & HG-SIL \\
\hline \multirow[t]{3}{*}{ Cis } & \multicolumn{2}{|l|}{ Carcinoma in situ $^{\mathrm{d}}$} & & HG-SIL \\
\hline & \multicolumn{2}{|l|}{ Bowenoid papulosis $^{d}$} & Perianal & HG-SIL \\
\hline & \multicolumn{2}{|l|}{ Bowen's disease $^{d}$} & Perianal & HG-SIL \\
\hline
\end{tabular}

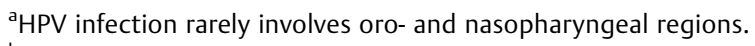

${ }^{\text {bSCC }}$ can involve all dermal as well as foregut and hindgut derived tissues in addition to anogenital zones.

'Immunohistochemical evaluation of p16 is required for AIN 2 to be denominated as H-SIL.

dHGD, Cis, Bowenoid papulosis, and Bowen's disease are historical terms categorized currently as H-SIL. 
Table 2 Stratification of HPV subtypes according to oncogenic risk. The nanovalent HPV vaccine is effective against those annotated in bold

\begin{tabular}{|c|c|}
\hline Risk & HPV subtypes \\
\hline High (Hr- HPV) & $16,18,31,33,35,39,45,51,52,56,58,59,68$ \\
\hline Probably high & $26,53,66,73,82$ \\
\hline Low (Ir-HPV) & $6,11,40,42,43,44,54,61,70,72,81$, CР6108 \\
\hline
\end{tabular}

Abbreviation: HPV, human papilloma virus.

epidermis through microabrasions. At the anogenital level, infection occurs almost exclusively during sexual intercourse, but could eventually be transmitted by sharing sex toys or similar items. Regular and proper condom use does not achieve complete protection against infection. HPV can be transmitted by contact with unprotected areas such as the vulva or the scrotum. ${ }^{8,9}$ Most patients do not use a condom from the beginning to the end of their sexual contacts. Microlesions in the anus are aggravated by scraping, excessive hygiene, and depilation or during defecation. Normal immune responses usually destroy the HPV virus. It persists and integrates within the host deoxyribonucleic acid (DNA) when cellular immunity fails. ${ }^{10}$ The integrated virus is present in more than 80 to $90 \%$ of SIL and SCC. ${ }^{11}$ Both the anal and cervical canals develop from the cloacal membrane. The fusion of endodermal and ectodermal tissues results in their respective squamocolumnar junctions. Normal metaplastic changes and abnormal dysplastic changes associated with HPV infection can occur in both areas. $^{4}$

\section{Current Nomenclature of Squamous Neoplastic Conditions}

The American College of Pathologists in conjunction with the American Society of Colposcopy and Cervical Pathology endorsed a unified nomenclature in 2012-Lower Anogenital Squamous Terminology (LAST). ${ }^{4}$ This classification divides anogenital HPV infections into LG-SIL (usually self-limited) and HG-SIL that have a greater potential to progress to SCC. LG-SIL includes -IN 1 and condyloma which are not considered pre-neoplastic. These low-grade lesions can progress to HG-SIL. -IN 2 and -IN 3 are both HG-SIL (-Table 3).

\section{Historical Terms in Perianal Disease}

High-grade dysplasia and carcinoma in situ are commonly used terms that are equivalent to HG-SIL. ${ }^{12}$ There are several terms applied to perianal lesions. Bowen's disease is the classic example. It is a diffuse form of PAIN-2 or 3 sometimes recognizable on physical diagnosis. It also falls into the category of HG-SIL with the LAST project denominations (-Fig. 2). Bowenoid papulosis is also a PAIN 2 or 3 (HG-SIL). Kreuter classified four forms of PAIN. They are listed in -Table $4 .^{13}$ Three variants are demonstrated in - Fig. 3.

\section{Risk Factors for Progression of ASIL to SCC}

The two population sectors at highest risk of progression from intraepithelial neoplasia to invasive anal SCC are human immunodeficiency virus positive (HIV $[+]$ ) MSM (Male who have Sex with Men) and immunocompromised individuals-particularly transplanted patients requiring chronic immunosuppression. ${ }^{14}$

A variety of immunocompromised conditions predispose individuals to developing anal cancer. The standardized incidence ratio for anal squamous disease is listed in -Table 5. ${ }^{15,16}$

Condylomas in immunocompromised patients present as voluminous, rapidly growing, exophytic lesions with a poorer response to treatment and a higher rate of recurrence. ${ }^{17}$ Solid organ transplant patients are at greater risk of SIL and SCC secondary to immunosuppressive therapy. ${ }^{18}$ The risk of anal SCC in this group is 4.54 times higher than the general population. ${ }^{19}$

Patients with inflammatory bowel disease can develop ASIL, SCC, and anal adenocarcinomas. Carcinogenesis in this setting is influenced by local and systemic chronic inflammation, immunosuppression by drugs and HPV infection. The cutaneous and mucosal lesions associated with the epithelization of the fistulous tracts may facilitate HPV entry into keratinocytes. The literature concerning the development of SCC in Crohn's perianal fistula disease is limited. ${ }^{20}$ However, appropriate vigilance for ASIL and SCC may be warranted. ${ }^{21,22}$

HIV (+) MSM have higher rates of perianal infection by multiple HPV genotypes. Historically, the progression of HGPAIN to SCC was only $5 \%{ }^{18}$ More recent work reported progression to SCC in $18.4 \%$ of in 550 HIV (+) individuals with HG-SIL. ${ }^{23}$ Other factors operant in the progression of ASIL to SCC include HPV infection, high-risk sexual

Table 3 The original World Health Organization (WHO) classification was replaced by the cytology-based Bethesda terminology. The LAST Project nomenclature is the current unifying standard

\begin{tabular}{|c|c|c|}
\hline WHO & Bethesda & LAST project \\
\hline Low-grade dysplasia/-IN 1 & L-SIL & $\begin{array}{l}\text { L-SIL } \\
\text { (condyloma, -IN 1) }\end{array}$ \\
\hline Moderate-grade dysplasia/-IN 2 & H-SIL & H-SIL (-IN 2) \\
\hline High-grade dysplasia/-IN 3 & $\mathrm{H}-\mathrm{SIL}$ & H-SIL (-IN 3) \\
\hline Carcinoma in situ & & H-SIL \\
\hline
\end{tabular}

Abbreviations: H-SIL, high-grade squamous intraepithelial lesion; IN, intraepithelial neoplasia; L-SIL, low-grade squamous intraepithelial lesion. 


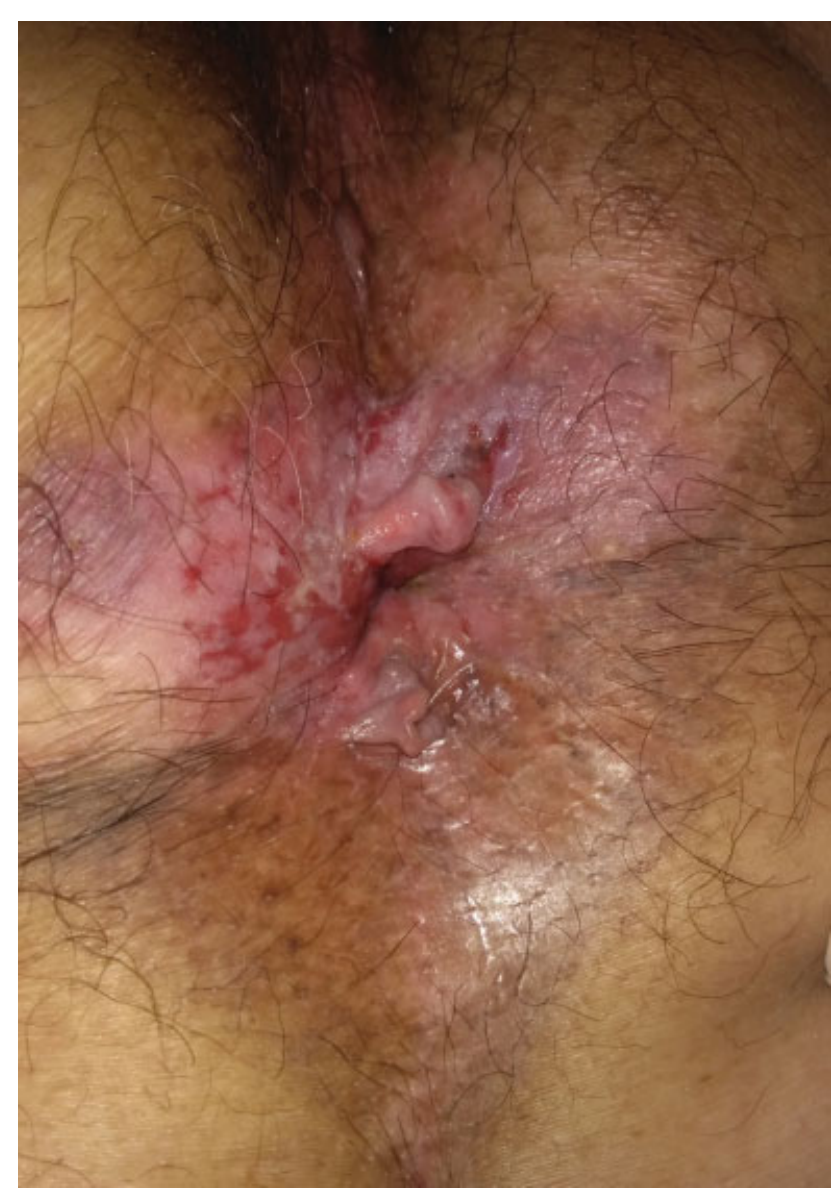

Fig. 2 Bowen's disease circumferentially present at the anal verge. Ulceration suggests invasion (Photo-L. Svidler López and L. La Rosa)

behavior, ${ }^{24}$ and HIV infection particularly if associated with CD4 levels below $200 \mathrm{cps} / \mathrm{mL}^{25}$ Unprotected anal intercourse, past history of H-SIL or SCC of the lower genital tract (LGT), anal condylomas, other STDs, smoking, and drug abuse are additional risk factors.

HG-SIL is statistically much less frequent in heterosexual women and men. H-SIL and SCC can be found in condylomas of HIV $(+)$ patients. HG-SIL or SCC were found in $47.1 \%$ of HIV (+) MSM who had only condyloma on clinical evaluation. HIV (-) MSM were found to have multiple foci of HG-SIL in their condylomas in $41.1 \%$. 5,26

HIV infection is a risk factor for the development of ASIL in women. HIV $(+)$ females with a history of LGT intraepithelial neoplasia pose a greater risk of developing AIN and PAIN ${ }^{27,28}$

Table 4 Kreuter's descriptions of four forms of PAIN
Multicentricity of the HPV infection contributes to this observation. The anal mucosa also acts as a viral reservoir favoring reinfections in the LGT. ${ }^{29,30}$ These observations underscore the importance of concomitant genital, perianal, and endoanal examination.

Two studies in predominantly immunocompetent women found a prevalence of AIN of 12 to $27 \%$ when accompanied with a diagnosis of -IN of the LGT. ${ }^{31,32}$ Women with HG-CIN had the highest risk of developing AIN. Immunosuppression, vulvar -IN, and anal intercourse are associated with AIN in the setting (sensitivity of $47 \%$ and a specificity of $86.2 \%$ ). ${ }^{32}$

It is important to consider that lesions persistent over time (chronic) are associated with an increased risk of SCC even if they originate from low-risk HPV infections. ${ }^{33}$

\section{Clinical Evaluation}

Patients presenting with condyloma endorse a variety of nonspecific symptoms. Many are asymptomatic but concerned about the perianal growths. Pruritus is a common complaint. Pain and bleeding may be present with larger lesions. Very large lesions may become markedly malodorous. Appropriate clinical interrogatories include sexual practices, prophylactic habits, and a history of other STD as well as all the other elements of a complete medical history. A focused examination of all anogenital zones is required including proctoscopy by qualified providers. The clinical spectrum of HPV is dramatic from isolated diminutive wartlike growths to voluminous conglomerations as illustrated in -Fig. 4.

Clinical inspection is generally sufficient to diagnose perianal condyloma. Biopsy is not required but may be helpful when the diagnosis is in doubt. Lack of response to medical treatment, rapid increase in size of lesions, or suspicion of malignancy is also valid indication for excisional biopsy.

Inspection and palpation are important components in physical diagnosis. Changes in color, presence of masses, painful induration, or ulceration should be noted. Many centers throughout the world use high-resolution anoscopy (HRA) as an adjunct to inspection and rectal examination. HRA is useful in the early detection of endo- and perianal HGSIL. It can guide selective biopsies and in the early diagnosis of microinvasive SCC (-Fig. 5).

HRA magnification is a complimentary technique for a precise clinical examination-especially when the diagnosis

\begin{tabular}{|l|l|l|}
\hline \multicolumn{2}{|l|}{ Perianal intraepithelial neoplasia (PAIN) signs } \\
\hline Class & Denomination & Characteristics \\
\hline I & $\begin{array}{l}\text { Bowenoid } \\
\text { papulosis }\end{array}$ & A form of H-SIL is characterized by slightly raised and well-defined brown or violaceous papules \\
\hline II & Erythroplastic & Presents many erythematous plaques similar to Queyrat's erythroplasia \\
\hline III & Leukoplastic & Flat, well-delimited and punctate lesions \\
\hline IV & Verrucous & Characterized by one or more exophytic lesions with a hyperkeratotic surface \\
\hline
\end{tabular}

Abbreviation: H-SIL, high-grade squamous intraepithelial lesion; PAIN, perianal intraepithelial neoplasia. 


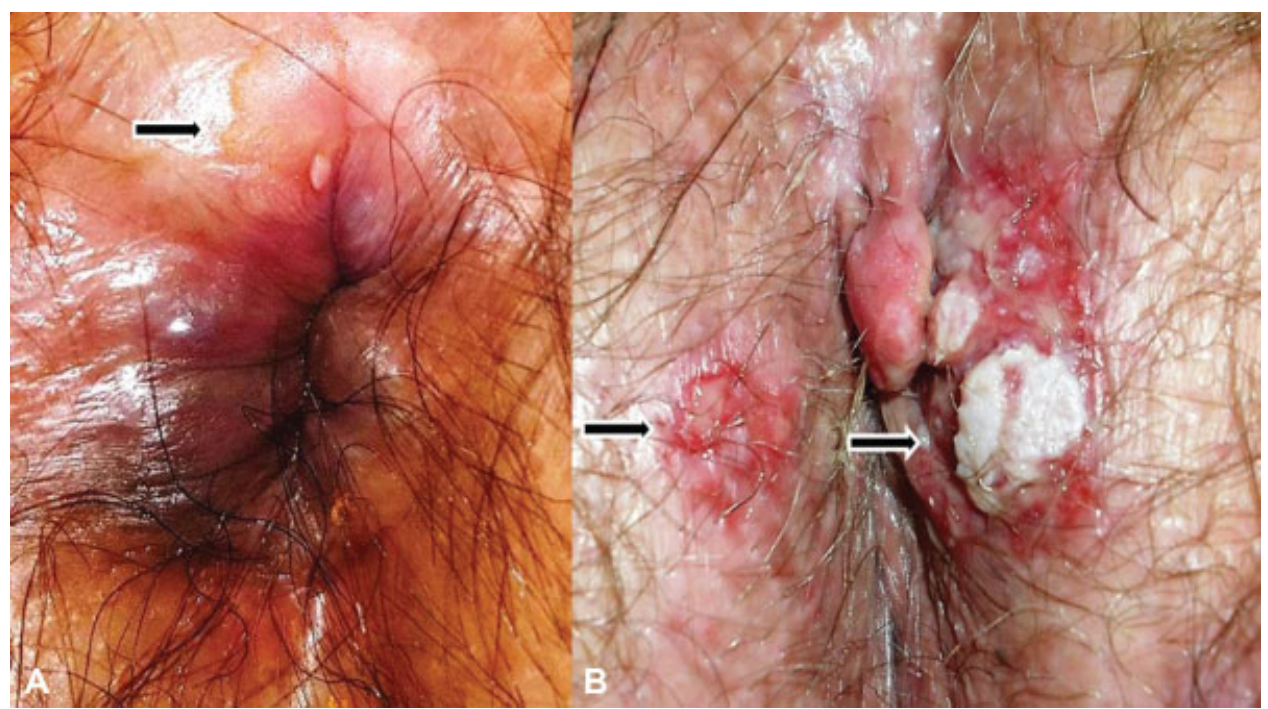

Fig. 3 (A) Perianal intraepithelial neoplasia 3 (PAIN 3) leukoplastic variant; (B) PAIN 3 erythroplastic/verrucous variants (Photo-L. Svidler López and L. La Rosa).

is in doubt in high-risk individuals. Perianal HRA helps discriminate between subtle, frequently diffuse, and lesions that are difficult to distinguish from benign skin alterations.

The procedure requires topical application of $5 \%$ acetic acid. It is important to recognize that not all acetowhite areas are PAIN. LG-SIL can be flat or slightly raised, acetowhite or warty, and may have unique vascular patterns referred as warty vessels in evidence. Punctate or mosaic vascular changes are rare. Their presence suggests HG-SIL. The distinction between LG-SIL and HG-SIL requires biopsy and histological confirmation. Lugol's iodine solution is not useful in the setting of keratinized epithelium. It is not used in the diagnosis of PAIN.

\section{Differential Diagnosis}

PAIN and numerous perianal dermatologic conditions may resemble one another. Flat lesions should be differentiated from dermatosis including lichen planus, psoriasis, scar leukoplakia as well as seborrheic and contact dermatitis. Anal lesions may represent systemic conditions also asso-

Table 5 Standardized incidence rate (SIR) for anal squamous disease according to the predisposing pathology

\begin{tabular}{|l|l|}
\hline Diagnosis & SIR \\
\hline HIV + & 81.1 \\
\hline Systemic lupus erythematosus & 26.9 \\
\hline Solid organ transplant patients & 14.4 \\
\hline Polyarteritis nodosa & 8.8 \\
\hline Wegener's granulomatosis & 12.4 \\
\hline Psoriasis & 3.1 \\
\hline Crohn's disease & 3.1 \\
\hline
\end{tabular}

Abbreviation: HIV +, human immunodeficiency virus positive; SIR, standardized incidence ratio. ciated with pruritus ani. HPV condyloma can be distinguished from syphilitic lesion by the presence of secondary syphilitic lessions. ${ }^{9}$ The differential diagnosis is difficult with verrucous herpes even with biopsies. ${ }^{34}$ Molluscum contagiosum has a central umbilication unlike condyloma (-Fig. 6) More aggressive and long-standing lesions in adults can suggest immunosuppression. ${ }^{35}$ Mibelli's porokeratosis is a group of pathologies that present with abnormal epidermal keratinization. They are usually asymptomatic but can produce pruritus. This condition presents in the anogenital region of immunocompromised patients. It can be difficult to differentiate from HPV without a histological diagnosis. ${ }^{36}$

\section{Treatment}

The treatment of PAIN initially requires the exclusion of endoanal lesions that are managed differently. There is no current consensus for the management of either PAIN or endoanal disease due to the lack of controlled studies. ${ }^{37}$ LGPAIN does not require a-priori treatment due to its low rate of malignancy and the possibility of spontaneous regression. Perianal condylomas more often require treatment because of the symptoms or fear of infecting others. Other factors include a desire to return to normal sexual activities quickly, for aesthetic and/or emotional reasons. It is unclear if HGPAIN requires treatment also because of a relatively low risk of malignant transformation. The inconclusive status of the dysplasia-carcinoma sequence is an additional mitigating factor into the decision to treat. Many centers worldwide recommend treatment because of the inability to predict which patients will develop cancer. Available treatments can eliminate ASIL but not the virus itself. Radical resection with clear microscopic margins does not prevent recurrence. -Fig. 7 represents a case in point. HPV may still be present in surrounding in apparently normal tissues. Tissue-preserving techniques are preferred over wide excision to prevent stenosis and incontinence. ${ }^{38}$ 
A

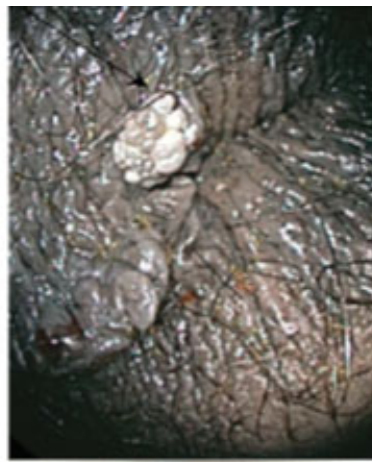

$\mathbf{E}$

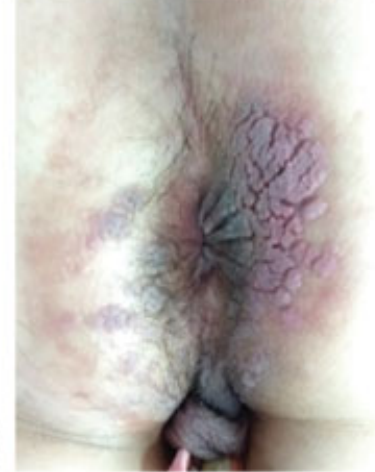

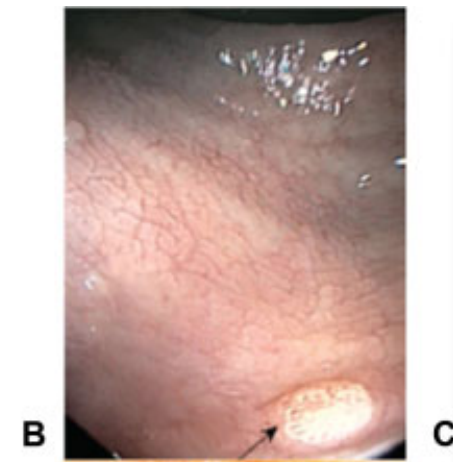

$\mathbf{F}$

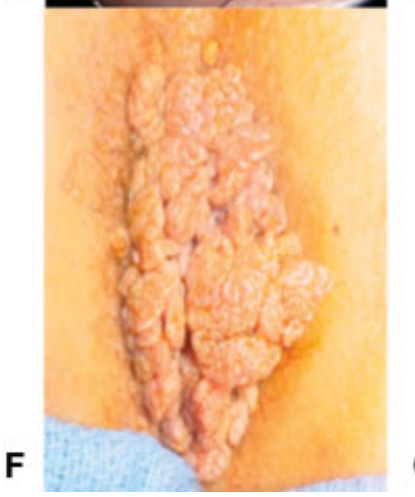

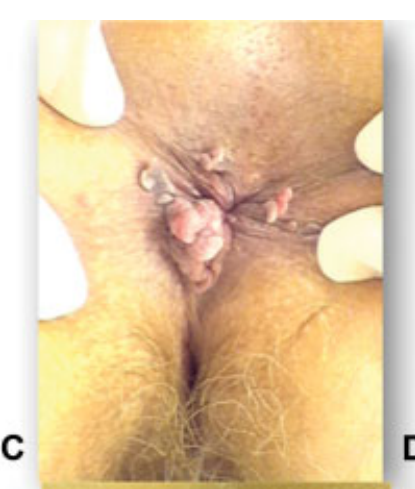

D

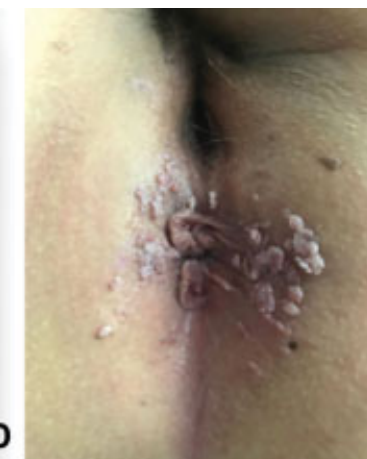

G

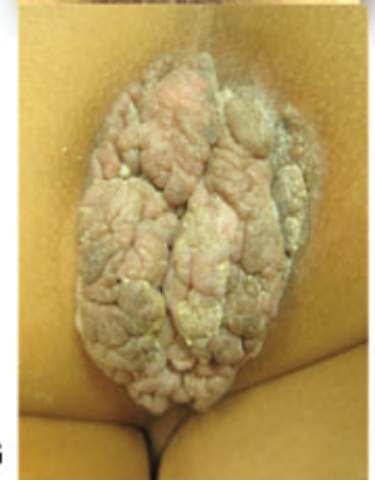

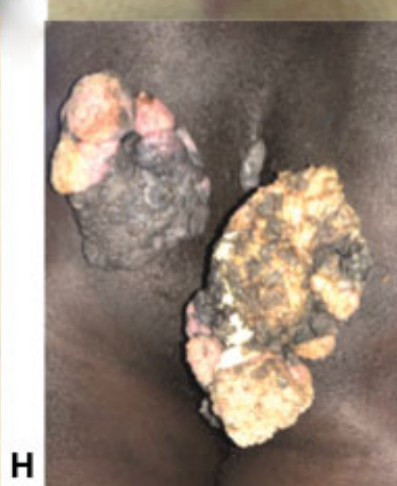

Fig. 4 The clinical presentations of anorectal condyloma are pleomorphic. Isolated external (A) or internal (B) lesions are in evidence. Lesions may be small and nonconfluent (C, D) or form large plaque-like conglomerates (E, F). Giant condyloma can surround the anal orifice (G) or present as multiple lobulated lesions (H) (Photos-L. Svidler López, L. La Rosa, A. Ortega)

Some topical treatments can be self-applied. Others required medically trained personnel for administration. Independently, there is a high recurrence locally in the perianal skin. ${ }^{38}$ Therapeutic options are mitigated by the number and characteristics of the lesions as well as location, physician's experience, patient preferences, and costs.

All SIL can be treated similarly regardless of their degree of dysplasia. Self-administered therapies include imiquimod, fluorouracil (5-FU), sinecatechin, and cidofovir creams. These have the advantage of suitability for outpatient use as well for multifocal disease. ${ }^{39,40}$ Topical treatments given by the physician include $90 \%$ trichloroacetic acid (TCA), podophyllin/podophyllotoxin, and intralesional interferon. Additional options include cryotherapy, infrared coagulation, electrocautery, and resectional surgery. ${ }^{37}$

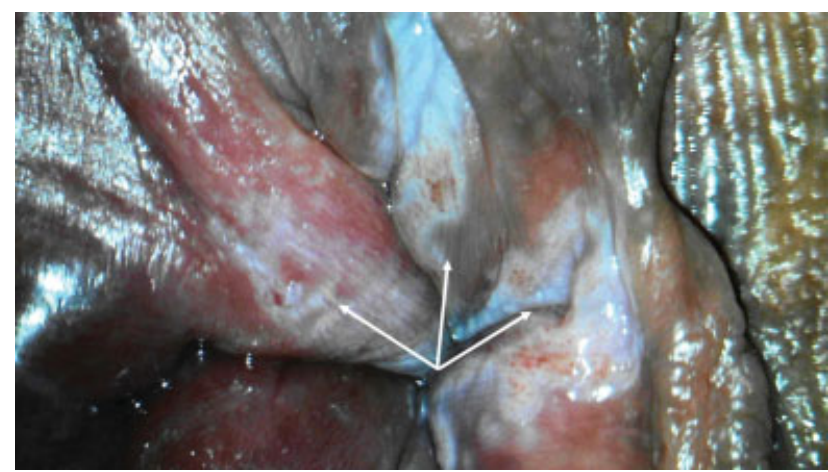

Fig. 5 Perianal intraepithelial neoplasia 3 lesion under $10 \times$ magnification on high-resolution anoscopy demonstrates aceto-white, flat, demarcated lesions with radial extensions in three trajectories. (Photo -L. Svidler López and L. La Rosa).
Ninety percent TCA represents a reasonable first-line treatment given its ease of use, low cost, and safety. It is especially useful for small perianal lesions. TCA has a 70\% response rate and is generally well-tolerated. TCA can produce a complete response or decrease the classification to

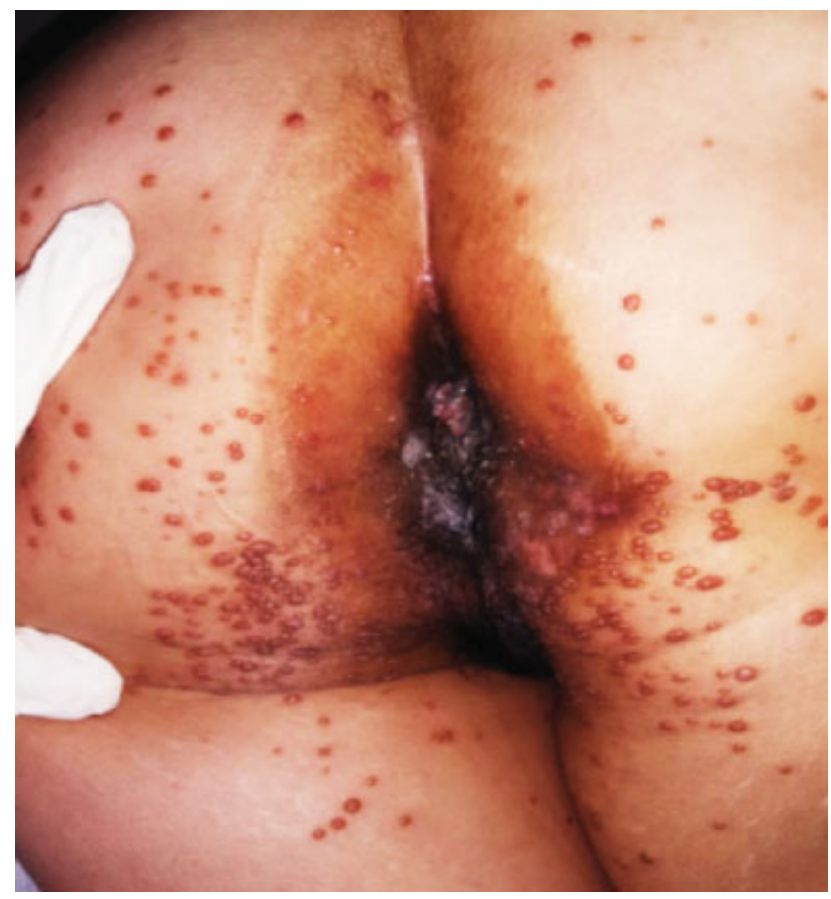

Fig. 6 Molluscum contagiosum is an uncommon sexually transmitted disease but important in the differential diagnosis of human papilloma virus infection (Photo-L. Svidler López and L. La Rosa). 


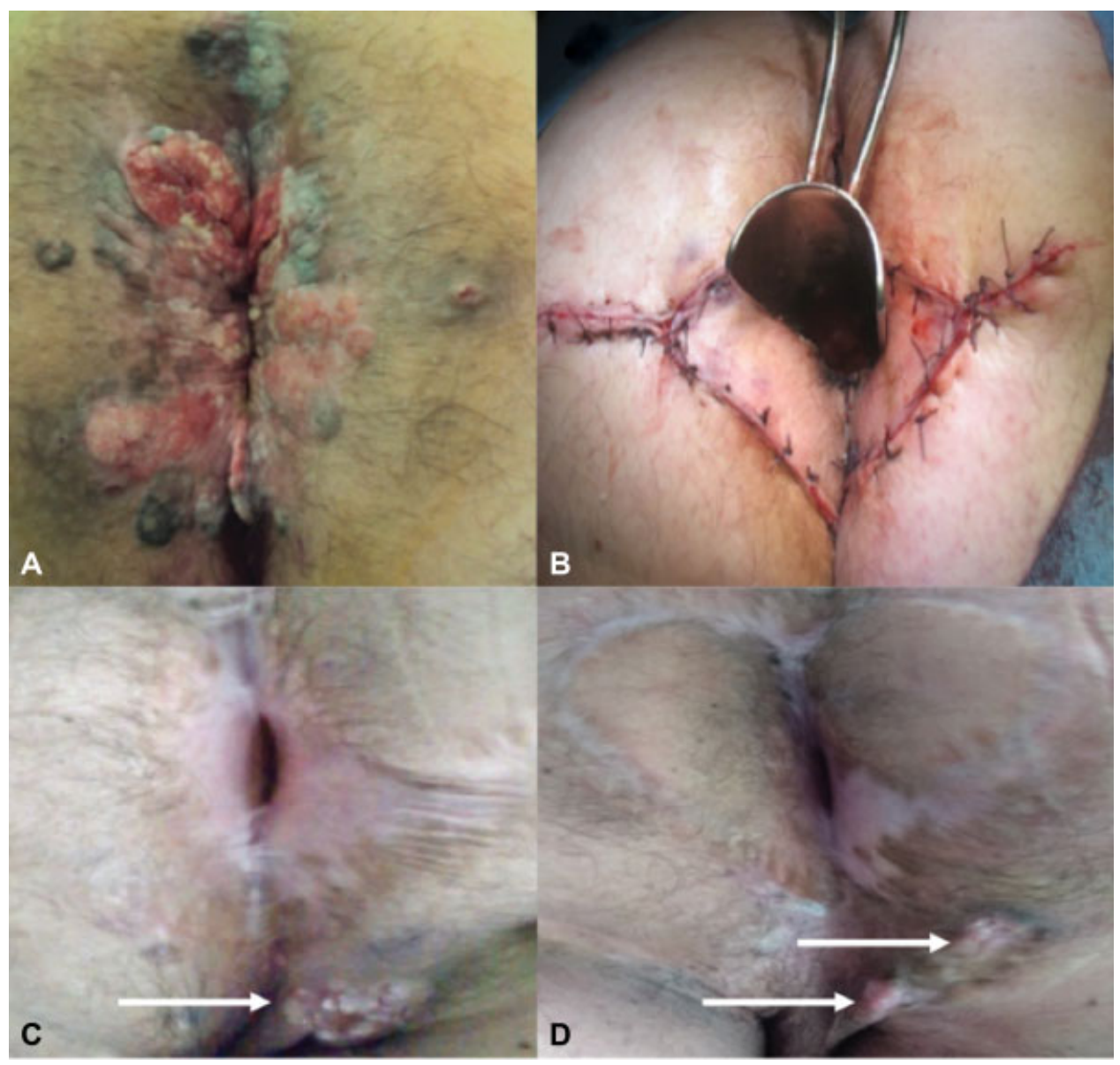

Fig. 7 (A) Circumferential high-grade perianal intraepithelial neoplasia with microinvasive foci was treated by wide local excision and (B) reconstructed with V-Y flaps. (C) Invasive squamous cell carcinoma (SCC) outside the flapped area was excised at 40 months later and (D) two SCC recurrences are evident 58 months later despite clear margins in all previous excisions. Progression to SCC is indicated with arrows. (Photos-L. Svidler López and L. La Rosa).

AIN 1 in HIV-positive MSM (73\%). AIN 2 to 3 responded similarly in $71 \%$. Younger HIV $(+)$ individuals with two or fewer lesions respond best to TCA ${ }^{41}$ ( - Fig. 8 ).

Imiquimod is an effective immunomodulatory drug as topical treatment in HIV $(+)$ and HIV (-) individuals. Treatment of perianal SIL with imiquimod decreases viral DNA load and reduces the number of genotypes at the end of therapy. ${ }^{42}$ It is particularly useful against multifocal or circumferential lesions because it treats obvious lesions and surrounding skin simultaneously. It can be used at $5 \%$ strength on alternate days or $3.75 \%$ strength on successive days. It produces a partial or complete response of $66 \%$ after 16 to 32 weeks. Imiquimod is generally well tolerated but may cause local irritation ${ }^{43}$ (-Fig. 9).

5-FU cream is useful for diffuse lesions. It decreases viral load locally. The partial or complete response rate is close to $60 \%$. 5-FU has a $50 \%$ recurrence rate at 6 months of followup. ${ }^{44}$ Local irritation is operant in both compliance and recurrence rates.

Podophyllin is a resin extracted from the root of the plant Podophyllum sp. Berberidaceae (mandrake). It contains numerous compounds including Podophyllotoxin that produce necrosis of HPV lesions. Most of studies concerning podophyllin/podophyllotoxin applications date back to the 1990s. More recent studies do not include it as a therapeutic option. Some groups report satisfactory results using $25 \%$ podophyllin in vaseline. ${ }^{45}$ Podophyllin is particularly useful for decreasing the size of bulky perianal lesions in the authors' experience ${ }^{45,46}$ ( - Fig. 10). They recommend once a week application during 4 to 6 weeks. It can produce pain and itching and should be avoided to use during pregnancy.

Cidofovir $1 \%$ cream is an analog of cytidine. It has activity against HPV. It achieves a complete response in 19\%. Fortysix percent had a greater than $50 \%$ volume reduction in lesions in the setting of HG-PAIN in HIV (+) hosts. The majority of patients had moderate local skin irritation. ${ }^{39}$ Its efficacy was also demonstrated in anogenital condyloma with a partial or complete response of 70 to $90 \% .{ }^{47}$ Topical therapies do not usually resolve lesions completely. They may often better serve as adjunctive treatment following ablative procedures when there is less volume of disease and better tolerance can be anticipated.

HRA can help guide ablative options including cryotherapy, electrocautery, infrared coagulation, and $\mathrm{CO}_{2}$ laser. It lessens the impact on anal physiology and sexual dysfunction in anoreceptive individuals. Infrared coagulation has been used in the ambulatory setting for the treatment of flat lesion. It is well tolerated in the treatment of HG-SIL ${ }^{48}$ ( - Fig. 11). 


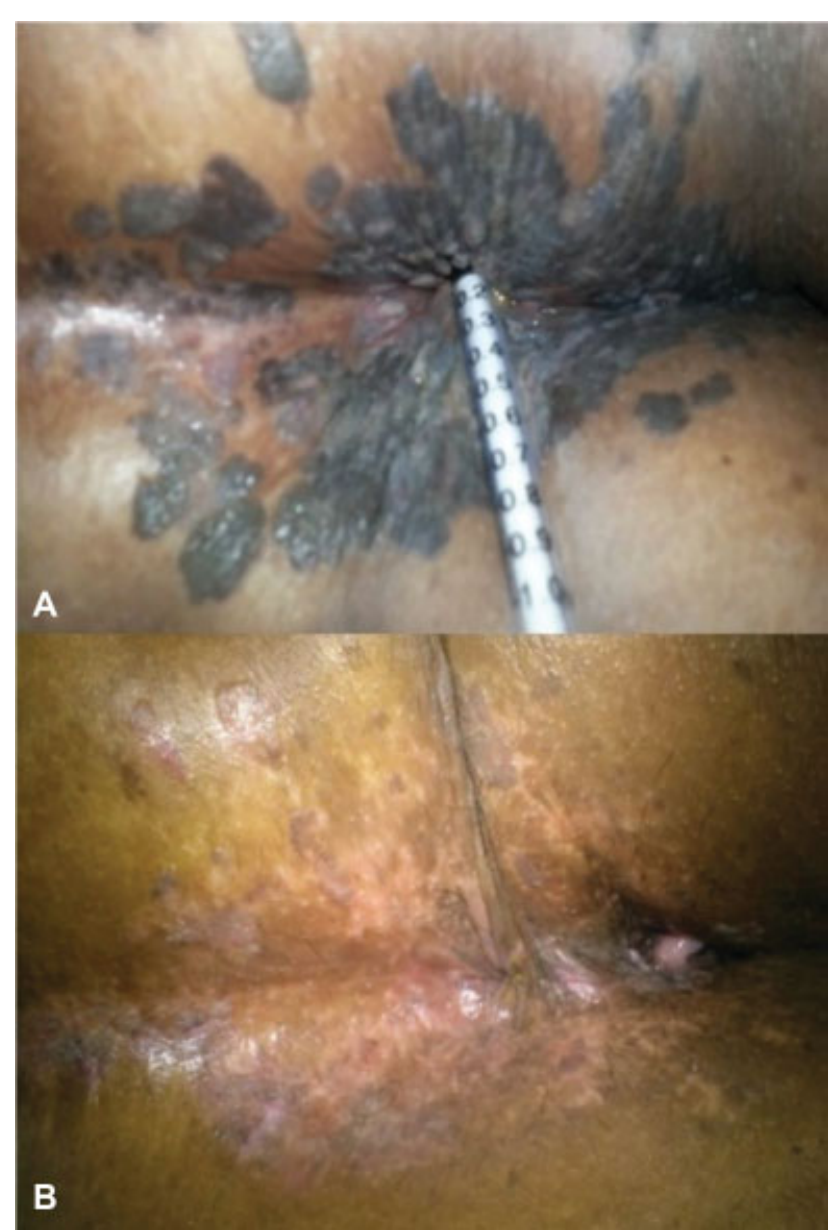

Fig. 8 (A) Bowenoid papulosis in human immunodeficiency virus positive patient with a (B) complete response to trichloroacetic acid 90\% and imiquimod (Photo-L. Svidler López and L. La Rosa).

Meta-analysis of cryotherapy, infrared coagulation, imiquimod, and podophyllin revealed similar results. ${ }^{49}$ Cryotherapy has more immediate adverse side effects including erythema, local irritation, and pain. Electrocautery has better clearance rates. $^{38}$ It achieved a $60 \%$ overall response rate in HG-AIN and HG-PAIN in HIV (+) MSM. There was a $33 \%$ partial or complete response in PAIN. ${ }^{50}$

Johnstone et al evaluated various HRA-directed ablative methods for the treatment of HG-PAIN in 70 HIV $(+)$ MSM. $^{38}$ HIV $(+)$ individuals have a 3.72 higher relative risk of HGPAIN than HIV (-) subjects. Kaplan-Meyer curves predicted a recurrence rate of 38,59 , and $68 \%$ at 1,3 , and 5 years, respectively, in $\mathrm{HIV}(+)$ individuals. These results are lower for perianal than anal canal disease. Ablation with $\mathrm{CO}_{2}$ laser, electrocautery, or infrared coagulation resulted in no cases of stenosis or incontinence. ${ }^{51}$

\section{Surveillance}

There are no universal guidelines for the follow-up of patients with the various stages and locations of HPV infection. ${ }^{52,53}$ There are several factors that should be taken into consideration. HPV infection is usually multicentric and involves normal appearing tissues. The natural history of

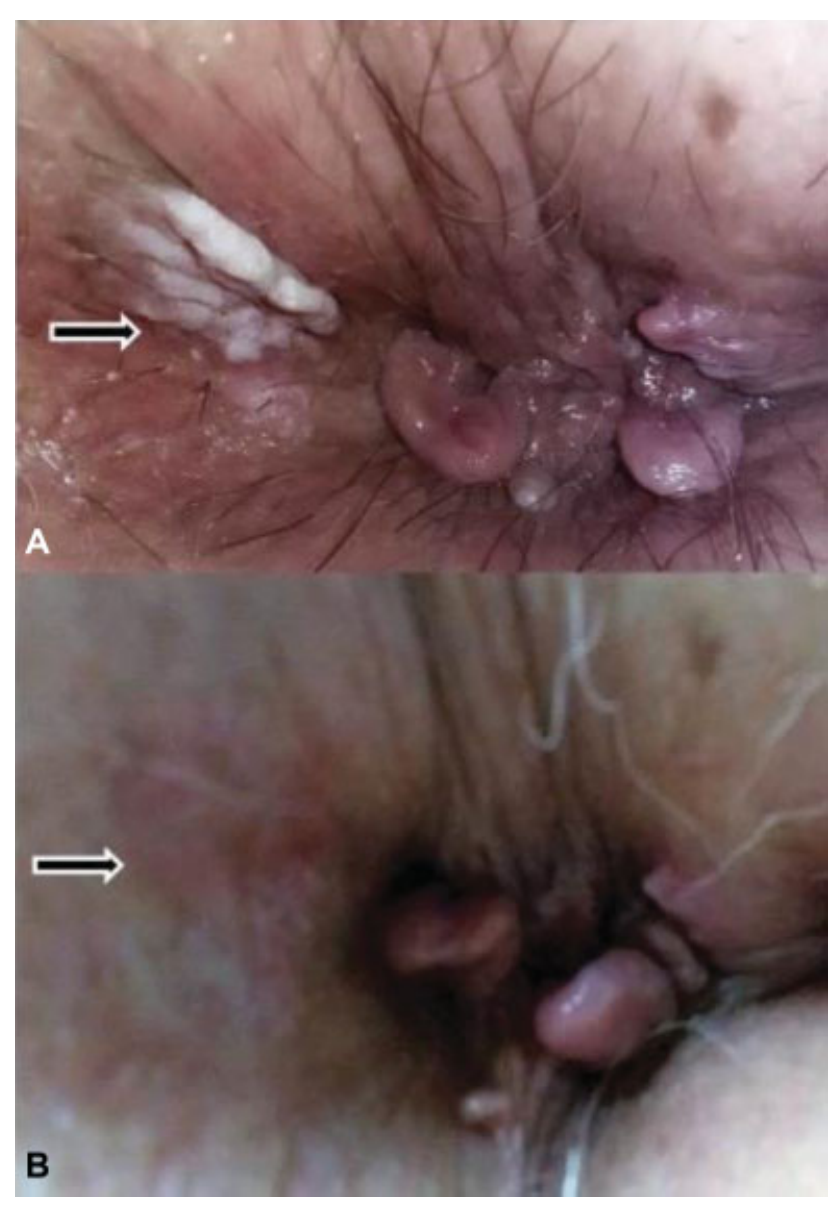

Fig. 9 (A) Perianal intraepithelial neoplasia 3 verrucous variant with a (B) complete response to imiquimod (Photo-L. Svidler López and L. La Rosa).

PAIN is not well established. It has been suggested that, in HIV (+) patients, the presence of PAIN represents a more advanced stage of disease patients and it is a marker for HGPAIN recurrence. ${ }^{51}$ There is agreement that there are more vulnerable groups including high-risk patients with HG-SIL or persistent lesions for more than 3 years. These individuals should be closely monitored.

Johnstone et al suggest evaluation at 6 to 12 weeks after the end of treatment with an anal digital examination and conventional anoscopy. ${ }^{38}$ Abnormal findings are studied with the aid of HRA. Anal cytology and HRA are performed at 6 months. In the absence of HG-SIL patients continue on follow uo every 3 to 6 months for 2 years and then on a yearly basis. Considering that the post-treatment approach commonly used for SCC is carried out every 3 to 6 months for the first 2 years, it would not be justified to make it stricter for PAIN. The aim of a selected strategy should be to detect early progressive or recurrent disease as well as invasion. ${ }^{36,37}$

\section{Early Detection (Screening)}

Some authors propose anal screening in at-risk populations based on the similarities with cervical cancer and the impact of cervical cancer screening. The aim in the hindgut region is screening for ASIL. It entails cytology, proctologic examination, 

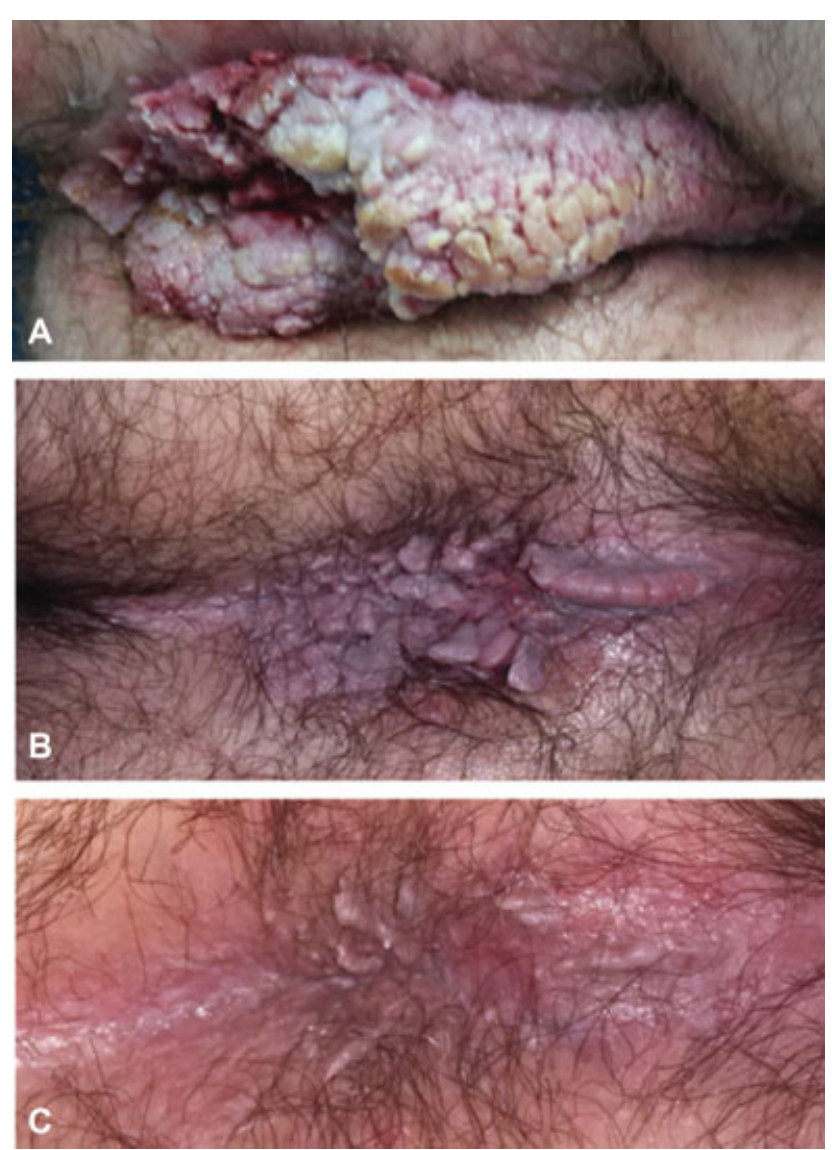

Fig. 10 (A) An advanced circumferential presentation of human papilloma virus infection (B) treated with topical podophyllin demonstrating (C) complete resolution. Podophyllin is useful in cytoreduction of bulky human immunodeficiency virus infection. (Photos-L. Svidler López and L. La Rosa).

and HRA. ${ }^{22,38}$ The progression from HG-PAIN to SCC at the anal margin is reported at $18.4 \%$. This observation underscores the need for perianal HG-SIL screening in high-risk patients. ${ }^{23}$
The Study for the Prevention of Anal Cancer ${ }^{54}$ and Anal Cancer HSIL Outcomes Research ${ }^{55}$ studies are currently underway. These studies will provide evidence regarding the natural evolution and response to treatment of HG-SIL in HIV (+) and MSM, respectively. The results should valuable information to define screening, treatment, and follow-up protocols.

\section{Editorial Comment}

Any lesion(s) within the anal canal should be considered potentially as an AIN. Those outside the anal canal over skin are PAIN. Lesions straddling the skin, anoderm, and mucosa are best considered AIN for all intents and purposes. Overlap between these zones is common. Isolated endoanal involvement of HPV is reported between 12.6 and $18 \%{ }^{53,56}$ Exclusive perianal involvement is reported at 32.3 to $55.1 \%$. Combined endoanal and surrounding anogenital involvement is common at 44.9 to $69 \% .^{53,57}$ These figures are important in considering treatment options that also overlap considerably. They also underscore the importance of proctologic examination in all cases (-Fig. 12).

Perhaps the single most important unanswered question is whether regimented follow-up evaluation actually decreases the incidence of SCC, morbidity, and mortality in at-risk individuals. In the absence of definitive data, discretion is the better part of valor. HPV infection affects normal appearing tissues. Recidivism is the norm. All individuals with HPV infections should be followed closely indefinitely.

There are no optimal therapies for HPV or the lesions that result from this infection. Wide-local excision does not prevent recurrence or progression to SCC. Tissue preserving techniques are better options. Therefore, mapping biopsies around the anus is probably an anachronistic concept. Selective use of HRA seems more reasonable. Sustained vigilance is the only practical approach to this complex problem.

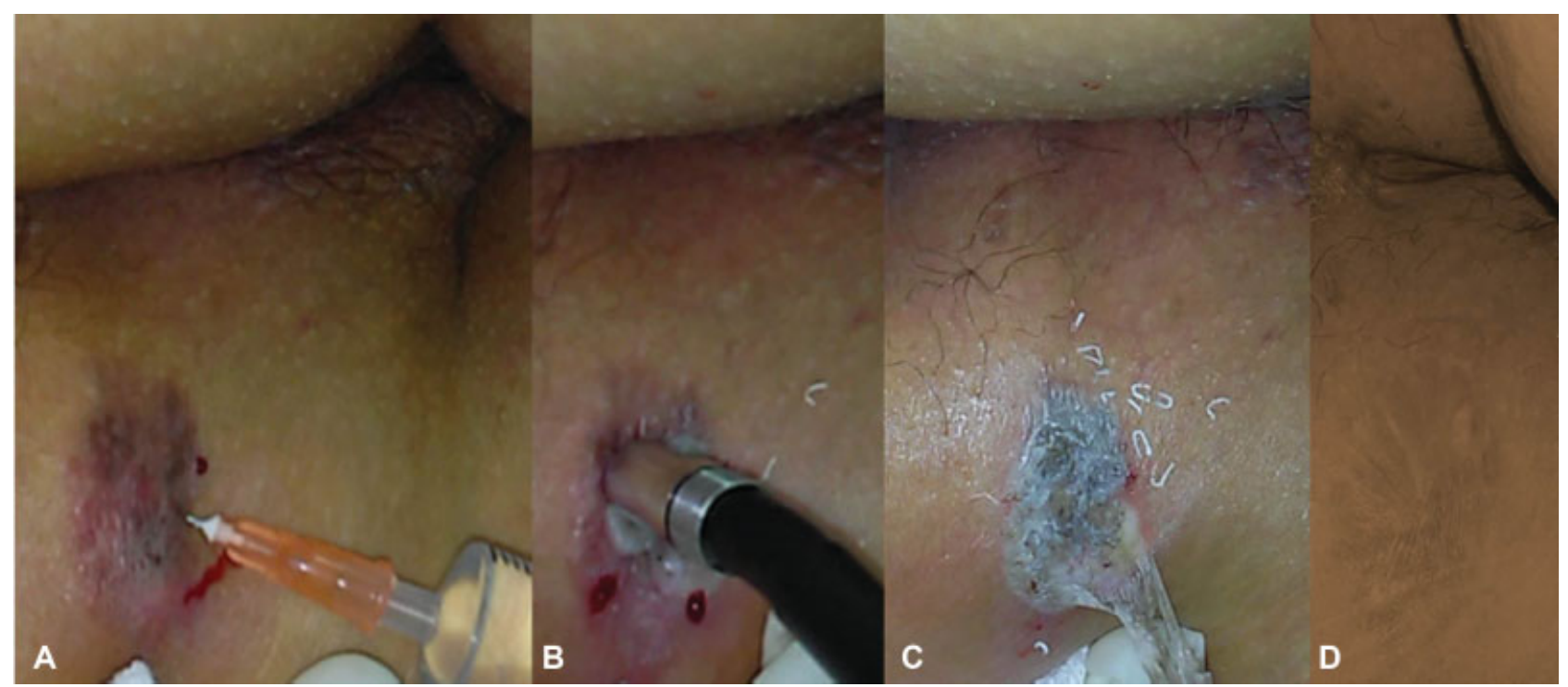

Fig. 11 (A) A perianal intraepithelial neoplasia lesion can be treated under local anesthesia (B) infrared coagulation application and (C) debridement of necrotized epidermis with (D) complete response evident on follow-up at 1 year. (Photos-L. Sviedler and L. La Rosa) 


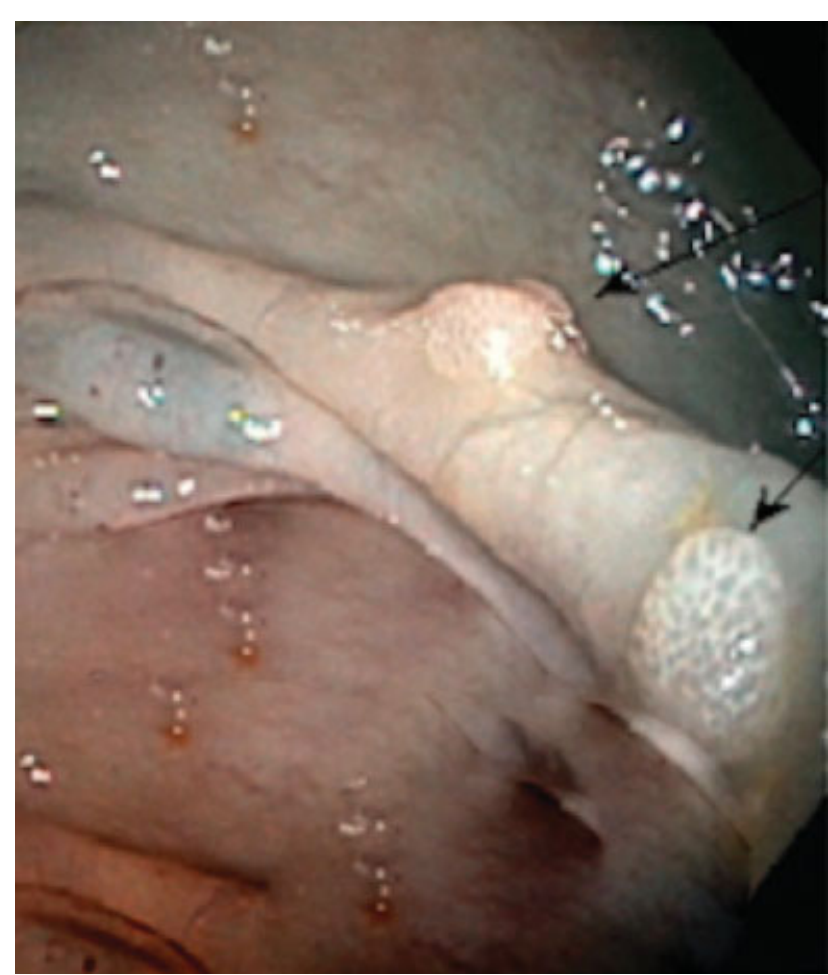

Fig. 12 Two condylomata (arrows) are evident on the third rectal valve of Houston. This case highlights the importance of proctologic evaluation of all human papilloma virus cases. Most rectal condylomata are found within $8 \mathrm{~cm}$ from the dentate line. These were detected at $15 \mathrm{~cm}$. (Photo-A. Ortega).

\section{Conflict of Interest}

None.

\section{References}

1 de Camargo CC, Tasca KI, Mendes MB, Miot HA, de Souza LdoR. Prevalence of anogenital warts in men with HIV/AIDS and associated factors. Open AIDS J 2014;8:25-30

2 Tommasino M. The human papillomavirus family and its role in carcinogenesis. Semin Cancer Biol 2014;26:13-21

3 Parkin DM. The global health burden of infection-associated cancers in the year 2002. Int J Cancer 2006;118(12):3030-3044

4 Darragh TM, Colgan TJ, Cox JT, et al; Members of LAST Project Work Groups. The lower anogenital squamous terminology standardization project for HPV-associated lesions: background and consensus recommendations from the College of American Pathologists and the American Society for Colposcopy and Cervical Pathology. Arch Pathol Lab Med 2012;136(10):1266-1297

5 Pimenoff VN, Félez-Sánchez M, Tous S, et al. Disagreement in high-grade/low-grade intraepithelial neoplasia and high-risk/ low-risk HPV infection: clinical implications for anal cancer precursor lesions in HIV-positive and HIV-negative MSM. Clin Microbiol Infect 2015;21(06):605.e11-605.e19

6 Palefsky J. Human papillomavirus and anal neoplasia. Curr HIV/ AIDS Rep 2008;5(02):78-85

7 Geh I, Gollins S, Renehan A, et al. Association of Coloproctology of Great Britain and Ireland (ACPGBI): guidelines for the management of cancer of the colon, rectum and anus-Anal cancer. Colorectal Dis 2017;19(Suppl 1):82-97

8 Holmes KK, Levine R, Weaver M. Effectiveness of condoms in preventing sexually transmitted infections. Bull World Health Organ 2004;82(06):454-461
9 Workowski KA, Bolan GA. Sexually transmitted diseases. Treatment guidelines, 2015. MMWR Recomm Rep 2015;64(RR03):1-137

10 Park IU, Palefsky JM. Evaluation and management of anal intraepithelial neoplasia in HIV-negative and HIV-positive men who have sex with men. Curr Infect Dis Rep 2010;12(02): 126-133

11 Pineda CE, Welton ML. Management of anal squamous intraepithelial lesions. Clin Colon Rectal Surg 2009;22(02):94-101

12 Salmo E, Haboubi N. Anal cancer: pathology, staging and evidence-based minimum data set. Colorectal Dis 2011;13 (Suppl 1):11-20

13 Kreuter A, Brockmeyer NH, Hochdorfer B, et al. Clinical spectrum and virologic characteristics of anal intraepithelial neoplasia in HIV infection. J Am Acad Dermatol 2005;52(04):603-608

14 van der Zee RP, Richel O, de Vries HJ, Prins JM. The increasing incidence of anal cancer: can it be explained by trends in risk groups? Neth J Med 2013;71(08):401-411

15 Sunesen KG, Nørgaard M, Thorlacius-Ussing O, Laurberg S. Immunosuppressive disorders and risk of anal squamous cell carcinoma: a nationwide cohort study in Denmark, 1978-2005. Int J Cancer 2010;127(03):675-684

16 Dreyer L, Faurschou M, Mogensen M, Jacobsen S. High incidence of potentially virus-induced malignancies in systemic lupus erythematosus: a long-term followup study in a Danish cohort. Arthritis Rheum 2011;63(10):3032-3037

17 Wieland U, Kreuter A, Pfister H. Human papillomavirus and immunosuppression. Curr Probl Dermatol 2014;45:154-165

18 Frisch M, Fenger C, van den Brule AJ, et al. Variants of squamous cell carcinoma of the anal canal and perianal skin and their relation to human papillomaviruses. Cancer Res 1999;59(03): 753-757

19 Skov Dalgaard L, Fassel U, Østergaard LJ, Jespersen B, Schmeltz Søgaard O, Jensen-Fangel S. Risk of human papillomavirus-related cancers among kidney transplant recipients and patients receiving chronic dialysis-an observational cohort study. BMC Nephrol 2013;14:137-147

20 Ruel J, Ko HM, Roda G, et al. Anal neoplasia in inflammatory bowel disease is associated with HPV and perianal disease. Clin Transl Gastroenterol 2016;7:e148

21 Slesser AA, Bhangu A, Bower M, Goldin R, Tekkis PP. A systematic review of anal squamous cell carcinoma in inflammatory bowel disease. Surg Oncol 2013;22(04):230-237

22 Roberts JR, Siekas LL, Kaz AM. Anal intraepithelial neoplasia: A review of diagnosis and management. World J Gastrointest Oncol 2017;9(02):50-61

23 Tinmouth J, Peeva V, Amare H, et al. Progression from perianal high-grade anal intraepithelial neoplasia to anal cancer in HIVpositive men who have sex with men. Dis Colon Rectum 2016;59 (09):836-842

24 Watson AJ, Smith BB, Whitehead MR, Sykes PH, Frizelle FA. Malignant progression of anal intra-epithelial neoplasia. ANZ J Surg 2006;76(08):715-717

25 Palefsky JM, Holly EA, Ralston ML, Jay N, Berry JM, Darragh TM High incidence of anal high-grade squamous intra-epithelial lesions among HIV-positive and HIV-negative homosexual and bisexual men. AIDS 1998;12(05):495-503

26 McCloskey JC, Metcalf C, French MA, Flexman JP, Burke V, Beilin LJ. The frequency of high-grade intraepithelial neoplasia in anal/ perianal warts is higher than previously recognized. Int J STD AIDS 2007; 18(08):538-542

27 Valari O, Koliopoulos G, Karakitsos P, et al. Human papillomavirus DNA and mRNA positivity of the anal canal in women with lower genital tract HPV lesions: predictors and clinical implications. Gynecol Oncol 2011;122(03):505-508

28 Hessol NA, Holly EA, Efird JT, et al. Anal intraepithelial neoplasia in a multisite study of HIV-infected and high-risk HIV-uninfected women. AIDS 2009;23(01):59-70 
29 Calore EE, Giaccio CM, Nadal SR. Prevalence of anal cytological abnormalities in women with positive cervical cytology. Diagn Cytopathol 2011;39(05):323-327

30 Véo CA, Saad SS, Nicolau SM, Melani AG, Denadai MV. Study on the prevalence of human papillomavirus in the anal canal of women with cervical intraepithelial neoplasia grade III. Eur J Obstet Gynecol Reprod Biol 2008;140(01):103-107

31 Tatti S, Suzuki V, Fleider L, Maldonado V, Caruso R, Tinnirello MdeL. Anal intraepithelial lesions in women with human papillomavirus-related disease. J Low Genit Tract Dis 2012;16(04): 454-459

32 ElNaggar AC, Santoso JT. Risk factors for anal intraepithelial neoplasia in women with genital dysplasia. Obstet Gynecol 2013;122(2 Pt 1):218-223

33 Cornall AM, Roberts JM, Garland SM, Hillman RJ, Grulich AE, Tabrizi SN. Anal and perianal squamous carcinomas and highgrade intraepithelial lesions exclusively associated with "lowrisk" HPV genotypes 6 and 11. Int J Cancer 2013;133(09): 2253-2258

34 Nadal SR, Calore EE, Manzione CR, Horta SC, Ferreira AF, Almeida LV. Hypertrophic herpes simplex simulating anal neoplasia in AIDS patients: report of five cases. Dis Colon Rectum 2005;48 (12):2289-2293

35 Basu S, Kumar A. Giant molluscum contagiosum - a clue to the diagnosis of human immunodeficiency virus infection. J Epidemiol Glob Health 2013;3(04):289-291

36 Ferreira FR, Lessa PP, Alvarenga ML. Genitogluteal porokeratosis case report. An Bras Dermatol 2013;88(03):438-440

37 Weis SE. Current treatment options for management of anal intraepithelial neoplasia. OncoTargets Ther 2013;6:651-665

38 Johnstone AA, Silvera R, Goldstone SE. Targeted ablation of perianal high-grade dysplasia in men who have sex with men: an alternative to mapping and wide local excision. Dis Colon Rectum 2015;58(01):45-52

39 Stier EA, Goldstone SE, Einstein MH, et al. Safety and efficacy of topical cidofovir to treat high-grade perianal and vulvar intraepithelial neoplasia in HIV-positive men and women. AIDS 2013; 27(04):545-551

40 Werner RN, Westfechtel L, Dressler C, Nast A. Self-administered interventions for anogenital warts in immunocompetent patients: a systematic review and meta-analysis. Sex Transm Infect 2017;93(03):155-161

41 Singh JC, Kuohung V, Palefsky JM. Efficacy of trichloroacetic acid in the treatment of anal intraepithelial neoplasia in HIV-positive and HIV-negative men who have sex with men. J Acquir Immune Defic Syndr 2009;52(04):474-479

42 Mahto M, Nathan M, O'Mahony C. More than a decade on: review of the use of imiquimod in lower anogenital intraepithelial neoplasia. Int J STD AIDS 2010;21(01):8-16

43 van der Snoek EM, den Hollander JC, van der Ende ME. Imiquimod $5 \%$ cream for five consecutive days a week in an HIV-infected observational cohort up to 32 weeks in the treatment of highgrade squamous intraepithelial lesions. Sex Transm Infect 2015; 91(04):245-247
44 Richel O, de Vries HJ, van Noesel CJ, Dijkgraaf MG, Prins JM. Comparison of imiquimod, topical fluorouracil, and electrocautery for the treatment of anal intraepithelial neoplasia in HIVpositive men who have sex with men: an open-label, randomised controlled trial. Lancet Oncol 2013;14(04):346-353

45 Nadal SR, Manzione CR, Couto Horta SH, De Moura Galvao V. Tratamento Tópico dos condilomas acuminados perianais em doentes HIV+. Rev Bras Coloproctol 1999;19(02):79-82 www. jcol.org.br/pdfs/19_2/01.pdf

46 Svidler López L. Manejo medico de condilomas anales. In: Svidler López L, Presencia GJ, Sidra GL, Pastore RLO, editors HPV:Guía de Manejo Multidisciplinario. Buenos Aires, Argentina: Nueva Libreria; 2016:89-95. (ISBN 978-987-42-1243-6)

47 Coremans G, Margaritis V, Snoeck R, Wyndaele J, De Clercq E, Geboes K. Topical cidofovir (HPMPC) is an effective adjuvant to surgical treatment of anogenital condylomata acuminata. Dis Colon Rectum 2003;46(08):1103-1108, discussion 1108-1109

48 Goldstone SE, Kawalek AZ, Huyett JW. Infrared coagulator: a useful tool for treating anal squamous intraepithelial lesions. Dis Colon Rectum 2005;48(05):1042-1054

49 Bertolotti A, Dupin N, Bouscarat F, Milpied B, Derancourt C. Cryotherapy to treat anogenital warts in nonimmunocompromised adults: systematic review and meta-analysis. J Am Acad Dermatol 2017;77(03):518-526

50 Siegenbeek van Heukelom ML, Gosens KCM, Prins JM, de Vries HJC. Cryotherapy for intra- and perianal high-grade squamous intraepithelial lesions in HIV-positive men who have sex with men. Am J Clin Dermatol 2018;19(01):127-132

51 Goldstone SE, Johnstone AA, Moshier EL. Long-term outcome of ablation of anal high-grade squamous intraepithelial lesions: recurrence and incidence of cancer. Dis Colon Rectum 2014;57 (03):316-323

52 Steele SR, Varma MG, Melton GB, Ross HM, Rafferty JF, Buie WD; Standards Practice Task Force of the American Society of Colon and Rectal Surgeons. Practice parameters for anal squamous neoplasms. Dis Colon Rectum 2012;55(07):735-749

53 Silvera RJ, Smith CK, Swedish KA, Goldstone SE. Anal condyloma treatment and recurrence in HIV-negative men who have sex with men. Dis Colon Rectum 2014;57(06):752-761

54 Machalek DA, Grulich AE, Hillman RJ, et al; SPANC Study Team. The Study of the Prevention of Anal Cancer (SPANC): design and methods of a three-year prospective cohort study. BMC Public Health 2013;13:946

55 Panther L(PI)) ANCHOR Study: Anal Cancer/HSIL Outcomes Research Study, (AMC Protocol \#A01) https://jcto.weill.cornell. edu/open_clinical_trials/anchor-anal-cancerhsil-outcomesresearch-study. Accessed 1/9/17

56 Delbello A, Colli C, Martínez TdelR, Trevisan G. Anal canal and rectal condylomatosis: exhaustive proctological examination and STD patients. Acta Dermatovenerol Alp Panonica Adriat 2010;19 (01):13-16

57 Mlakar B. Proctoscopy should be mandatory in men that have sex with men with external anogenital warts. Acta Dermatovenerol Alp Panonica Adriat 2009;18(01):7-11 